\title{
INFORMATION SEEKING BEHAVIOUR OF HOMEOPATHY STUDENTS: A CASE STUDY
}

\author{
Deepa John
}

Faculty, Dept. of Library and Information Science,

St. Berchmans College (Autonomous) Changanassery, Kottayam, Kerala, India

\section{Dr. Krishnapriya K.M,}

Dept. of Library and Information Science,

St. Berchmans College (Autonomous) Changanassery, Kottayam, Kerala, India

Yamuna P.B,

Faculty, Dept. of Library and Information Science,

St. Berchmans College (Autonomous) Changanassery, Kottayam, Kerala, India

\begin{abstract}
Growth of information is excessive in Medical science like many other sciences, and which is critically dependent on up-to-date information. The rapid proliferation of information in this era has important implications for the education of health professionals including medical students. Information and communication technologies have provided opportunities for medical libraries to meet the needs of their users in a much better way. The present study is undertaken to find out the information needs and seeking behavior of medical students in Athurasramam N.S.S. Medical College, Kurichy. The main goal of the study is to understand and identify the ways adopted by the B.H.M.S students in Athurasramam N.S.S. Homeo Medical College, Kurichy for collecting information and find out whether the existing library facilities are useful for their information needs.
\end{abstract}

Keywords: Information need, Information seeking behavior, Medical students.

Cite this Article: Deepa John, Dr. Krishnapriya K.M, Yamuna P.B, Information Seeking Behaviour of Homeopathy Students: A Case Study. International Journal of Library \& Information Science, 7(2), 2018, pp. 61-70.

http://iaeme.com/Home/issue/IJLIS?Volume=7\&Issue=2

\section{INTRODUCTION}

Information is vital resource and needed by everyone including students and faculties to enhance their academic performance. The users visit libraries in quest for information but when the same users face problems such as absence of proper knowledge regarding type of information resources, purpose of seeking or searching information etc. it affects the use of 
library resources. The users feel that library could not fulfill their needs and that they are wasting time in searching for the information as well obtaining need based information. Keeping these considerations in mind the present study has been undertaken to assess the information seeking behavior of medical students to fulfill needs of users from libraries in digital information era and solve their problems. Information seeking and information needs of library users are changing due to many factors and there is a necessity to assess ISB and usage of resources of medical students. The present study is an effort made towards this aspect and reviews the medical student's attitude towards using resources, awareness of resources, methods of seeking information, problems faced, use of free information resources etc.

\section{REVIEW OF LITERATURE}

Thukaram, K. ${ }^{1}$ focused a study on Information Seeking Behavior of Research scholars at Central University Libraries in Hyderabad. The study was undertaken to determine the information seeking behavior and library use by the researchers in the Central University Libraries. The overall objective of the study was to determine the information requirements of researchers and also to determine their awareness of available library services. The study collected data on the information requirements of research scholars. The study also aims to find out the nature and degree of constrains experienced in the process of information seeking. A pre ordered structured questionnaire was prepared anticipating the information needs, seeking behavior and use pattern of the users of Central University Libraries researchers (Ph.D.). A survey method was used for data collection. Out of 150,110 filled in questionnaires were returned by the users. Findings showed that library is mostly used by the users to visit library to study and preparing research. The $20 \%$ of users to visit the library for borrowing materials and using e-resources. The library system of Central University libraries might be capable of handling the collection of information according to the need and demands of the researchers. Findings also indicate the guidance and use of library resources and services is necessary to help researchers meet some of their information requirements.

Bhanu, Parthap ${ }^{2}$ investigated the information needs and seeking behavior of the users of Lala Rajpat Rai University of Veterinary and Animal Sciences, Hisar (India).The main objective of the present study appraises information use and seeking behavior of faculty members, research scholars and PG students for their reference and use of appraising other to emulate. A sample of 200 users was taken from various categories of users covering faculty members, research scholars and postgraduate students. A questionnaire was designed and distributed among the users to collect the primary data. Statistical tools like percentage analysis are used to analyze the data. The paper discusses various aspects of information needs and seeking information, such as knowledge of information resources, frequency of use, usefulness of library resources, information search preferences, adequacy of library collection and Information Technology IT based information, barriers in seeking information and perception towards helpfulness of library staff and so on. The survey method with the aid of well-designed questionnaire is used to conduct the research. Random sampling has been adopted and the data has been collected with the pre tested questionnaire. The findings revealed that majority of research scholars search their information from e-resources. Cent percent research scholars were using internet facilities and e-resources, whereas PG students were using CD-ROM data bases. While others are satisfied with the performance of library staff. In the end preferably in- charge of readers Service Division, should focus on assisting of this study is to analyze the behavior of users towards their information needs and usage pattern. 


\section{OBJECTIVES}

- To examine the information needs and seeking behavior of medical students in Athurasramam N.S.S. Medical College, Kurichy.

- To know the use and level of satisfaction of information sources and services provided by the library.

- To determine the impact of IT on information seeking of medical students.

- To identify the barriers encountered by the medical students in seeking information.

- To make appropriate suggestions if necessary for the improvement of the systems and services of Athurasramam N.S.S. Homeo Medical College Library.

\section{METHODOLOGY}

Survey method using questionnaire was adopted to collect data and the investigator interviewed the digital librarian for the same. Observation method also used to gather data for study. The population of the study is the students in Athurasramam N.S.S. Homeo Medical College, Kurichy. The college offers B.H.M.S course .The total number of students during the period of study is 243 and all of them have been included in the study. The investigator distributed 243 questionnaires to the students and 232 were received from them. The percentage of response is $95.47 \%$. The percentages of medical students who do not respond are $4.53 \%$.

\section{ANALYSIS OF DATA}

\subsection{Information Need}

\subsubsection{Purpose of Information Seeking}

A question was asked to know the purpose of seeking information.

Table I Purpose for Information Seeking

\begin{tabular}{|c|c|c|c|c|c|c|c|}
\hline $\begin{array}{c}\text { SI } \\
\text { NO }\end{array}$ & & & \multicolumn{5}{|c|}{ No of Respondents and Percentage } \\
\hline & \multirow[t]{2}{*}{ Purposes } & & \multicolumn{5}{|c|}{ Grade of preference } \\
\hline & & 1 & 2 & 3 & 4 & 5 & 6 \\
\hline \multirow{2}{*}{1} & \multirow{2}{*}{$\begin{array}{l}\text { Improving clinical } \\
\text { decision making }\end{array}$} & 85 & 68 & 38 & 24 & 15 & 8 \\
\hline & & $(36.64 \%)$ & $(29.31 \%)$ & $(16.38 \%)$ & $(10.34 \%)$ & $(6.47 \%)$ & $(3.45 \%)$ \\
\hline \multirow{2}{*}{2} & \multirow{2}{*}{ Keeping up to date } & 84 & 63 & 45 & 29 & 5 & 17 \\
\hline & & $(36.21 \%)$ & $(27.16 \%)$ & $(19.40 \%)$ & $(12.5 \%)$ & $(2.16 \%)$ & $(7.33 \%)$ \\
\hline \multirow[b]{2}{*}{3} & \multirow{2}{*}{$\begin{array}{l}\text { Sharing knowledge with } \\
\text { colleagues }\end{array}$} & 20 & 35 & 61 & 48 & 33 & 39 \\
\hline & & $(8.62 \%)$ & $(15.09 \%)$ & $(26.29 \%)$ & $(20.69 \%)$ & $\begin{array}{c}(14.22 \% \\
)\end{array}$ & $(16.81 \%)$ \\
\hline \multirow{2}{*}{4} & $\begin{array}{c}\text { Answering colleagues/ } \\
\text { Patient }\end{array}$ & 31 & 40 & 46 & 57 & 46 & 18 \\
\hline & Questions & $(13.36 \%)$ & $(17.24 \%)$ & $(19.83 \%)$ & $(24.57 \%)$ & $\begin{array}{c}(19.83 \% \\
)\end{array}$ & $(7.76 \%)$ \\
\hline \multirow[b]{2}{*}{5} & \multirow{2}{*}{$\begin{array}{c}\text { Writing reports/ Research } \\
\text { paper }\end{array}$} & 10 & 17 & 28 & 42 & 40 & 85 \\
\hline & & $(4.31 \%)$ & $(7.33 \%)$ & $(12.07 \%)$ & $(18.10 \%)$ & $\begin{array}{c}(17.24 \% \\
)\end{array}$ & $(36.64 \%)$ \\
\hline \multirow[b]{2}{*}{6} & To prepare for Seminars/ & 10 & 28 & 34 & 31 & 63 & 47 \\
\hline & Conferences/Workshops & $(4.31 \%)$ & $(12.07 \%)$ & $(14.66 \%)$ & $(13.36 \%)$ & $\begin{array}{c}(27.16 \% \\
)\end{array}$ & $(20.26)$ \\
\hline
\end{tabular}




\subsubsection{Table 1 reveals that}

\subsubsection{First Preference}

When $36.64 \%$ of students seek information for Improving clinical decision making, $36.21 \%$ seek it for Keep up to date followed by Answering colleagues/ Patient questions $13.36 \%$, Sharing knowledge with colleagues $8.62 \%$ and an equal percentage seek information for both Writing reports/ Research papers and prepare for Seminars/ Conferences/ Workshops $4.31 \%$.

\subsubsection{Second Preference}

When $29.31 \%$ of students seek information for Improving clinical decision making, $27.16 \%$ seek information to Keep up to date followed by Answering colleagues/ Patient questions $17.24 \%$, preparation of Seminars/ Conferences/ Workshops $12.07 \%$ and to Write reports/ Research papers $7.33 \%$.

\subsubsection{Third Preference}

$26.29 \%$ of students seek information for Sharing knowledge with colleagues, $19.83 \%$ seek information for Answering colleagues/ Patient questions followed by to Keep up to date $19.40 \%$, Improving clinical decision making $16.38 \%$, for preparation of Seminars/ Conferences/ Workshops $14.66 \%$ and to Write reports/ Research papers $12.07 \%$.

\subsection{Information Seeking Behavior}

\subsubsection{Time spend for Information seeking per day}

Respondents were asked to indicate the time spend for information seeking activities per day.

Table 2 Time Spend for Information Seeking Per Day

\begin{tabular}{|c|c|c|c|}
\hline SI.NO & Time Spend & No. of Respondents & Percentage \\
\hline 1 & $\begin{array}{c}\text { More than three } \\
\text { Hours }\end{array}$ & 67 & $28.88 \%$ \\
\hline 2 & $1-3$ Hours & 65 & $28.02 \%$ \\
\hline 3 & Less than 1 hour & 100 & $43.10 \%$ \\
\hline
\end{tabular}

Table 2 reveals that majority $43.10 \%$ of students spend less than 1 hour for the information seeking activities followed by more than 3 hours, $28.88 \%$ and $1-3$ hours $28.02 \%$ per day.

\subsubsection{Communication Channels used for Information Seeking}

A question was asked to know about the commonly used communication channels for information seeking.

Table 3 Communication Channels

\begin{tabular}{|c|c|c|c|}
\hline SI.NO & Communication channels & No of Respondents & Percentage \\
\hline 1 & Meet personally & 128 & $55.17 \%$ \\
\hline 2 & Face to face discussion & 149 & $64.22 \%$ \\
\hline 3 & E-mails & 92 & $39.66 \%$ \\
\hline 4 & Telephone & 65 & $28.01 \%$ \\
\hline 5 & Postal mails & 0 & 0 \\
\hline 6 & Fax & 2 & $2 \%$ \\
\hline
\end{tabular}


Table 3 indicates that multiple responses were received for this question. Face to face Discussion is the major communication channel used by medical students $(64.22 \%)$ followed by Personal meeting 55.17\%, E-mails $39.66 \%$ and Telephone $28.01 \%$. Only $2 \%$ of them used Fax as their communication channel.

\subsubsection{Preferred Formats}

Respondents were asked to specify their preferred format of information sources.

Table 4 Preferred Formats

\begin{tabular}{|l|c|c|c|}
\hline SI.NO & Formats & No of respondents & Percentage \\
\hline 1 & Print & 42 & $18.10 \%$ \\
\hline 2 & Electronic & 26 & $11.20 \%$ \\
\hline 3 & Audio visual & 95 & $40.95 \%$ \\
\hline 4 & Print \& electronic & 107 & $46.12 \%$ \\
\hline
\end{tabular}

Table 4 reveals that most $46.12 \%$ of the students prefer both Print and Electronic information sources followed by $40.95 \%$ of the students are using Audio visual formats, $18.10 \%$ use Printed information whereas $11.20 \%$ used electronic information sources.

\subsubsection{Use of Consortia/Portals/Databases for Information Seeking}

Respondents were asked to identify which are the consortia/ portals/ databases they used for seeking information.

Table 5 Use of Consortia/Portals/Databases

\begin{tabular}{|c|c|c|c|}
\hline S1. No. & $\begin{array}{c}\text { Consortia/ } \\
\text { Portals/Databases }\end{array}$ & $\begin{array}{c}\text { No. of } \\
\text { Respondents }\end{array}$ & Percentage \\
\hline 1 & PubMed & 43 & $18.53 \%$ \\
\hline 2 & Homeo book & 134 & $57.75 \%$ \\
\hline 3 & Whole Health Now & 12 & $5.17 \%$ \\
\hline 4 & H.O.P.E Online portal & 75 & $32.33 \%$ \\
\hline 5 & NTR MEDNET Consortia & 0 & 0 \\
\hline
\end{tabular}

Table 5 shows that multiple responses were received for this question. Majority $57.75 \%$ of medical students used Homeo book for their information seeking whereas $32.33 \%$ of them used H.O.P.E Online portal followed by $18.53 \%$ use PubMed and $5.17 \%$ use Whole Health Now.

\subsubsection{Sources of Extensive Information}

The respondents were asked to indicate the sources they depend for finding extensive information relating to their topic. 
Deepa John, Dr. Krishnapriya K.M, Yamuna P.B

Table 6 Sources of Extensive Information

\begin{tabular}{|c|c|c|c|}
\hline Sl.NO & Sources & No. of Respondents & Percentage \\
\hline 1 & College library & 178 & $76.72 \%$ \\
\hline 2 & Other medical libraries & 27 & $11.64 \%$ \\
\hline 3 & Professional institutions & 33 & $14.22 \%$ \\
\hline 4 & Homeopathic portals/databases & 110 & $50 \%$ \\
\hline 5 & Seminars/Conferences/Workshops & 100 & $43.10 \%$ \\
\hline
\end{tabular}

As per Table 6 multiple responses were received for this question. Majority of students $76.72 \%$ depends College library for seeking extensive information relating to their subject of interest followed by Homeopathic portals/databases 50\%, Seminars or Conferences or Workshops $43.10 \%$, Professional institutions $14.22 \%$ and other medical libraries $11.64 \%$.

\subsubsection{Tools Used for Locating Information}

Respondents were asked to specify the tools used for locating information.

Table 7 Tools Used for Locating Information

\begin{tabular}{|c|c|c|c|}
\hline Sl.NO & Tools & No. of respondents & Percentage \\
\hline 1 & Consulting library Staff & 85 & $36.64 \%$ \\
\hline 2 & Direct search in the Shelf & 132 & $56.90 \%$ \\
\hline 3 & Searching E-resources & 15 & $6.47 \%$ \\
\hline 4 & Through OPAC & 0 & 0 \\
\hline
\end{tabular}

Table 7 shows that more than half $56.90 \%$ of medical students locate information through direct search in the shelf while $36.64 \%$ of them Consult library staff and only $6.47 \%$ used various e-resources. None of them are using OPAC for locating information.

\subsubsection{Methods Adopted for Seeking Information}

Respondents were asked to specify the methods adopted for seeking information relating to their field of interest.

Table 8 Methods Adopted for Seeking Information

\begin{tabular}{|c|c|c|c|}
\hline SI.NO & Methods & No of respondents & Percentage \\
\hline 1 & Current issues of journals & 72 & $31.03 \%$ \\
\hline 2 & CAS services & 0 & 0 \\
\hline 3 & Seminars/Conferences & 112 & $48.28 \%$ \\
\hline 4 & Through internet & 188 & $81.03 \%$ \\
\hline 5 & Online/CD ROM databases & 51 & $22 \%$ \\
\hline 6 & $\begin{array}{c}\text { Personal communication with } \\
\text { subject experts }\end{array}$ & 45 & $19.40 \%$ \\
\hline
\end{tabular}

Table 8 shows that multiple responses were received for this question. Majority $81.03 \%$ of the students use Internet for seeking information relating to their field of interest followed by Seminars/ Conferences $48.28 \%$, Current issues of journals $31.3 \%$, Online/ CD ROM data bases $22 \%$ and Personal communication with subject experts is $19.40 \%$.

\subsubsection{Criteria for Selecting Databases or Portals}

A question was asked to specify the criteria for selecting various databases/ portals meet their health information needs. 
Information Seeking Behaviour of Homeopathy Students: A Case Study

Table 9 Criteria for Selecting Databases or Portals

\begin{tabular}{|c|c|c|c|c|c|}
\hline SI.NO & Databases/Portals & Accessibility & Accuracy & $\begin{array}{c}\text { Ease of } \\
\text { Understanding }\end{array}$ & Reliability \\
\hline \multirow{2}{*}{1} & \multirow{2}{*}{ PubMed Central } & 113 & 38 & 56 & 24 \\
\hline & & $(48.70 \%)$ & $(16.38 \%)$ & $(24.14 \%)$ & $(10.34 \%)$ \\
\hline 2 & $\begin{array}{l}\text { Materiamedica \& } \\
\text { Repertory database }\end{array}$ & 0 & 0 & 0 & 0 \\
\hline 3 & CORE-Hom & 0 & 0 & 0 & 0 \\
\hline \multirow{2}{*}{4} & \multirow{2}{*}{ Homeo book } & 98 & 35 & 30 & 42 \\
\hline & & $(42.24 \%)$ & $(15.09 \%)$ & $(12.93 \%)$ & $(18.10 \%)$ \\
\hline \multirow{2}{*}{5} & \multirow{2}{*}{ Whole Health Now } & 29 & 65 & 34 & 13 \\
\hline & & $(12.5 \%)$ & $(28.02 \%)$ & $(14.66 \%)$ & $(5.60 \%)$ \\
\hline \multirow{2}{*}{6} & H.O.P.E Online & 124 & 22 & 20 & 38 \\
\hline & Portal & $(53.45 \%)$ & $(9.48 \%)$ & $(8.62 \%)$ & $(16.38 \%)$ \\
\hline 7 & Science Direct & 0 & 0 & 0 & 0 \\
\hline
\end{tabular}

\subsubsection{Table 9 reveals that}

\subsubsection{Accessibility}

More than half $53.45 \%$ of medical students stated H.O.P.E Online portal is accessible followed by PubMed central $48.70 \%$, Homeo book $42.24 \%$ and $12.5 \%$ Whole health now.

\subsubsection{Accuracy}

$28.02 \%$ of medical students stated Whole health Now is accurate followed by PubMed central $16.38 \%$, Homeo book $15.09 \%$ and $9.48 \%$ stated H.O.P.E Online.

\subsubsection{Ease of Understanding}

$24.14 \%$ of medical students stated PubMed central is easily understandable followed by Whole health Now $14.66 \%$, Homeo book $12.93 \%$ and $8.62 \%$ stated H.O.P.E Online portal.

\subsubsection{Reliability}

$18.10 \%$ of medical students stated Homeobook is reliable followed by H.O.P.E. Online portal $16.38 \%$, PubMed Central $10.34 \%$ and $5.60 \%$ stated Whole health now.

\subsection{Information Technology}

\subsubsection{Use of Search Engines}

Respondents were asked to specify the search engines they used for seeking information.

Table 10 Use of Search Engines

\begin{tabular}{|c|c|c|c|}
\hline SI.NO & Search Engines & No. of Respondents & Percentage \\
\hline 1 & Bing & 30 & $12.93 \%$ \\
\hline 2 & Altavista & 15 & $6.46 \%$ \\
\hline 3 & Yahoo & 15 & $6.46 \%$ \\
\hline 4 & Google & 231 & $99.57 \%$ \\
\hline
\end{tabular}


As per Table 10 multiple responses were received for this question. Majority $99.57 \%$ of students prefer to search information through Google followed by $12.93 \%$ preferred Bing, $6.46 \%$ equally preferred both Alta vista and Yahoo.

\subsubsection{Purpose of using Internet}

Respondents were asked to specify their purpose of using internet in the order of priority.

Table 11 Purpose of using Internet

\begin{tabular}{|c|c|c|c|c|c|c|}
\hline SI NO & Purpose & \multicolumn{3}{|c|}{ Order of Preference } & \\
\hline \multirow{2}{*}{1} & & $\mathbf{1}$ & $\mathbf{2}$ & $\mathbf{3}$ & $\mathbf{4}$ & $\mathbf{5}$ \\
\hline \multirow{2}{*}{2} & \multirow{2}{*}{ For Communication } & 76 & 45 & 42 & 12 & 8 \\
\cline { 3 - 7 } & \multirow{2}{*}{ For Updating Knowledge } & 167 & 56 & 41 & 38 & 10 \\
\cline { 3 - 7 } & & $71.98 \%)$ & $24.14 \%)$ & $17.67 \%)$ & $16.38 \%)$ & $(4.31 \%)$ \\
\hline \multirow{2}{*}{3} & For prepare for Classroom & 45 & 29 & 36 & 47 & 65 \\
\hline \multirow{2}{*}{4} & Assignment & $19.40 \%)$ & $(12.5 \%)$ & $15.52 \%)$ & $20.26 \%)$ & $28.02 \%)$ \\
\hline \multirow{2}{*}{5} & \multirow{2}{*}{5} & 17 & 28 & 44 & 56 & 84 \\
\cline { 3 - 7 } & For Career development & $(7.33 \%)$ & $12.07 \%)$ & $18.97 \%)$ & $24.14 \%)$ & $36.21 \%)$ \\
\cline { 3 - 7 } & \multirow{2}{*}{ Recreation } & 1 & 21 & 58 & 61 & 91 \\
\cline { 3 - 7 } & & $(0.43 \%)$ & $(9.05 \%)$ & $(25 \%)$ & $26.29 \%)$ & $39.22 \%)$ \\
\hline
\end{tabular}

\subsubsection{First Preference}

$71.98 \%$ of students use internet for Updating Knowledge while $32.75 \%$ use internet for Communication. $19.40 \%$ of them use internet to prepare for Class room assignment while $7.33 \%$ use for Career development. Only $0.43 \%$ use internet for Recreation.

\subsubsection{Second Preference}

$24.14 \%$ of students prefer internet for Updating knowledge while $19.39 \%$ use internet for Communication. $12.07 \%$ use for Career development and $12.5 \%$ use internet for preparing for Classroom assignments. $9.05 \%$ of students to use it for Recreation.

\subsubsection{Third Preference}

$25 \%$ use internet to for Recreation while $18.97 \%$ use it for Career development. $18.10 \%$ use internet for Communication whereas $17.67 \%$ use internet for Updating knowledge and $15.52 \%$ use it for preparation for Classroom assignments.

\subsection{Problems}

\subsubsection{Problems in Information Seeking}

A question was asked to specify the problems they face while seeking medical information. 
Table 12 Problems in Information Seeking

\begin{tabular}{|c|c|c|c|}
\hline SI NO & Problems & No. of Respondents & Percentage \\
\hline 1 & $\begin{array}{c}\text { Inadequate material } \\
\text { Collection }\end{array}$ & 67 & $28.88 \%$ \\
\hline 2 & $\begin{array}{c}\text { Library staff unwilling for } \\
\text { Service }\end{array}$ & 85 & $36.64 \%$ \\
\hline 3 & $\begin{array}{c}\text { Non availability of sources } \\
\text { and services }\end{array}$ & 55 & $23.71 \%$ \\
\hline 4 & Inconvenient working hours & 45 & $32.76 \%$ \\
\hline 5 & $\begin{array}{c}\text { Lack of knowledge in using } \\
\text { library facilities }\end{array}$ & 98 & $42.24 \%$ \\
\hline 6 & $\begin{array}{c}\text { Too much information on } \\
\text { the internet }\end{array}$ & 167 & $71.98 \%$ \\
\hline 7 & Inadequate qualified staff & & $19.40 \%$ \\
\hline
\end{tabular}

Table 12 indicates that multiple responses were received for this question. Majority $71.98 \%$ of respondents stated that their main problem while seeking information is Inadequate qualified staff, $42.24 \%$ stated Too much information on the internet is the problem followed by Library staff unwilling for service $36.64 \%$, Lack of knowledge in using library facilities $32.76 \%$, Inadequate material collection $28.88 \%$ and Non availability of sources and services $23.71 \% .19 .40 \%$ of respondents stated that Inconvenient working hours is their main problem while seeking information.

\section{MAJOR FINDINGS}

- Analysis revealed that majority of the medical students seek information for improving clinical decision making and keeping them up to date in their field.

- It is evident from the analysis that majority of the medical students spend less than 1 hour per day on information seeking activities.

- Majority of the medical students attested that they prefer face to face communication and personal meetings where as they seldom use postal mails as communication channels.

- Analysis revealed that students like to read in both print and electronic format.

- Majority of the medical students explore Homeobook while searching information and other important consortiums in their field are relatively less used.

- It is evident from the analysis that majority of the medical students depend college library for extensive information relating to their topic.

- Majority of the medical students locate their preferred information through direct search in the shelf. Further analysis revealed that OPAC is not all used to locate information.

- Analysis revealed that majority of medical students adopted Internet for seeking information. Further it is revealed that Seminars/ Conferences are the next used method for seeking information.

- Accessibility is the major criteria for selecting databases/portals in their field whereas accuracy and reliability are the less used.

- Majority of the medical students indicated the need for training to use library resources. 
- Majority of the medical students specified that unqualified library staff is their major problem while seeking information. Majority of them pointed out information overload as a problem while using internet.

\subsection{Suggestions}

- Qualified library staff must be appointed to provide effective and efficient services to the medical students.

- The library staff may be equipped with sufficient ICT knowledge and browsing skills by the means of formal training programmes.

- User Education programmes needed to be conducted to educate the users on Use of Search Engines, Rating the electronic resources, Use of available resources and Use of Library OPAC.

- The Medical Library should be adequately stocked with more current and up-to-date information materials including journals and other serial publications.

- Medical students very seriously require user education programmes, especially the periodical training on computer and communication technology as this would go a long way in equipping them with the requisite skills needed to explore information in the library using modern facilities.

- Library should as a matter of policy ensures that provide assistance to medical students, especially those who may have difficulties in searching for needed information or using the facilities of the library.

\section{CONCLUSION}

Results of the study shows that even though the medical students use various resources and services, there is low use of quality information resources such as online databases, e-journals etc. The study revealed that the students are not getting proper orientation/ guidance and assistance from the library staff which is very necessary for the effective use of information sources and services. The study also pointed out the non-availability of various sources and services to be provided by a medical college library.

\section{REFERENCES}

[1] Thukaram, K. "Information seeking behavior of research scholars at Central University libraries in Hyderabad: A study." International Journal of Information Science Sources and Service 5.2 (2015): 39-44.

[2] Bhanu, Parthap. "Information needs and seeking behavior of users of Lala Lajpat Rai University of Veterinary and Animal Sciences, Hisar (India)." PEARL: A Journal of Library and Information Science 10.2(2016). 